\title{
The Impact of Electronic Management on Human Resource Development
}

\author{
Assad Ahmad Abdelqader Alsakarneh ${ }^{1}$, Shen Chao Hong ${ }^{2}$ \\ ${ }^{1} \mathrm{PhD}$ Student, Affiliation: Central South University \\ ${ }^{2}$ Professor, Central South University
}

\begin{abstract}
This study aims to identify the impact of electronic management on the development of human resources, it deals with the concept of e-governance, objectives and areas, as well as the concept of human resources, and strategic importance of human resources and goals, and the changes imposed by the electronic management of human resources.
\end{abstract}

Keywords: Electronic management; e-governance; Human Resource Development

\section{Introduction}

When activated, electronic management and human resource development are highlighted elements of modern management with tremendous advances in information systems and the invasion of the world's so-called era of globalization that has been talked about trading at the end of the last century. It is no doubt that the activation of electronic management and development of human resources for the effective and upgrading depends on the optimization process including continuing to improve the performance of the organization in the long run.

In the development of electronic management and human resources, two necessities are considered in achieving the objectives of the organization or whatever activity and thus improve the performance of the organization. This helps to raise the level of the organization's performance, and continuous improvement of the operations of the Organization of e-governance and improve the performance of human resources in the organization, as well as do the necessary research to provide information on an urgent basis, which helps in identifying and addressing problems repeated with regard to improving the organization's performance and administrative obstacles.

Based on aforementioned, interest developed in the development of human resources associated with activation of electronic management in various levels and, in particular, human resources information systems, and is seeking in particular to the impact of e-government in the development of human resources to address in order to contribute to the improvement of the organization's performance.

\section{Problem Statement}

E-governance is the result of technical and technological development in the field of work and activities of organizations. The availability of resources and human private development by decision-makers in any administrative system has become a traditional and electronic necessity of administrative process so that these organizations remain stead fast against the currents of change scientific and technical sound manner for the exercise of workers organizations.

It can show the problem of the study were more evident by raising the following questions:

- What is the role of e-government in the development of human resources?

- What is the impact of the development of human resources at the organization's performance?

- The extent to which the development of human resources plays an intermediary role in enhancing the impact of the contents of e-governance at the organization's performance.

\section{The importance of the study}

- This study is important through the growing perception of human resources on the one hand and the role of information system within the institution of the hand and in general the importance of our research show the following elements:

- The importance acquired by the subject view the current situation through which the economic institutions that require attention to human resources as a delimiter fundamental to the success or failure of institutions, particularly in the light of globalization.

- The importance of information system and its impact on the economies of the institution in improving profitability and the development of competitiveness and raise the wage rates of the workforce.

- The targeting information system in institutions in general, and economic institutions, in particular its creation can activate human resources management style, human performance and directing better levels.

\section{Background}

(Abyan 2000) aimed to detect the most prominent barriers to the electronic system, which is facing managers in the electronic information systems application. This study was conducted to (200) men and women leaders in Riyadh, where he was distributing 500 questionnaires returned them (240) are the sample questionnaire study entitled "Obstacles in the internal mail systems from the perspective of leaders." In-depth scientific study showed that the most prominent 


\section{International Journal of Science and Research (IJSR) \\ ISSN (Online): 2319-7064}

Index Copernicus Value (2013): 6.14 | Impact Factor (2014): 5.611

obstacles electronic system application density paperwork and lack of compatibility with the rapid development of the programs and the lack of infrastructure as well as the availability of low readiness network speed dialing, and the large number of workers in one section and poor training and rehabilitation.

(Al-Otaibi 2005) this a study which aimed to reveal the importance of e-feasibility and motivate employees and train them in the use of modern technology and media studies. The study used questionnaires to conduct method. This study was conducted on a number of government institutions that apply the electronic system. The study showed that the lack of information-processing centers computer with the necessary printers, speakers, printing paper, frequent breakdowns in computers and the Internet, the small number of computer and Internet devices in the enterprise, the difficulty, not the institution connect with the Internet, not Internet presence in the home, the Internet slow to open Program pages, a few dedicated to take advantage of Internet services time, the loss of a great time in mobility between reality and pages on the Internet, the lack of time to browse the web having to do the work. But in the case of institutions appropriate processing electronics, the application of the electron system is one of the types of education, which contributes significantly to the acceleration of human rehabilitation for the application of e-government.

(Brdoe Pedroni, 1996) study aimed to reveal the importance of using technology in the field of institutions. This study was conducted on some institutions in South Aalonz. The study used screening method for the collection of the results of the staff at things used modern technology. The study showed that the new technology reduces the role of the employer. It also helped that modern technology staff cooperate with each other to produce the integrated work. The advantage of the technology found in the study that it helps employees to evaluate their own work. And help them to save their work in several types of technology to not lose. The study showed the use of technology to facilitate the work of the communication process, which helped them to improve production.

(Clay 2000) a study which aimed to identify the technological and training skills to the employee in the state institutions. To an appropriate extent won him the qualities that distinguish it from other workers to improve the quality of production. The researcher made up questionnaire (33) the adequacy of training technology is built according to the measurements developed by the International Association for the use of technology, and the study sample consisted of 146 employees in the organizations of the United States of America, in addition to the Director and Head of information Systems sector centers.

The results indicated that the employees have the competencies of information technology managers less than forecast information centers. While managers declined from international measures responses. The researcher recommended that employ information technology within IT organizations, and understanding of informational communication process and appreciate the importance of information technology in the preparation, development, implementation and evaluation of business strategies.

\section{Methodology}

Researcher relied on descriptive analytical method that allows an understanding of the extent of the contribution of the electronic administration in the development of human resources. The research also will depend in part on the theoretical literature theory and philosophical treatises that dealt with this topic.

\section{Electronic Management}

\section{The Concept of E-Government}

.Electronic management is an integrated electronic system which depends on the communications and information technology to transform the administrative manual labor work carried out by digital and modern technology.

E-governance as an administrative term is defined as: a set of regulatory processes between the beneficiary and the sources of information by electronic means to achieve the objectives established by the planning, production and operation and follow-up and development. The beneficiary is the references in government departments, or the client's business, or employee of any organization. (Mohammed, 2007)

E-governance is defined as: "the exploitation of management information and communications technology to measure and improve and develop the various administrative processes within the organization". (Abdel Fattah 2003)

E-Management : those existing administrative process to take advantage of the unique capabilities of the Internet and business networks in the planning, direction, and control of resources, the core of the organization and other capacity without limits in order to achieve its goals". (Nagam 2004) E-governance: "the use of a mixture of technology to business performance and accelerate this performance and the creation of an advanced mechanism for the exchange of information within the organization and between them and other organizations". (Ahmed, 2003).

Electronic management procedurally in this study as: the use of information and communication technology in the administrative process for the development of human resources in the organization of (planning, organization, implementation, supervision, monitoring and evaluation), in order to improve their performance and enhance their competitive position.

\section{Electronic Management Goals}

If any organization achieve success factors at the beginning of the project. The goals are then derived in the organization at the end of the project. They can be summarized as follows (Raafat 1999) (Abdel-Fattah.2004).

1) The provision of services to the beneficiaries in a satisfactory manner and within 24 hours a day, seven days a week, including the weekend.

2) Small-equipped place to save the electronic information. 


\section{International Journal of Science and Research (IJSR) \\ ISSN (Online): 2319-7064}

Index Copernicus Value (2013): 6.14 | Impact Factor (2014): 5.611

3) Achieve the speed required for the completion of work procedures and appropriate Financial cost.

4) Find unable to cope with the requirements of the technical age society.

5) Deepen the concept of transparency and away from patronage.

6) Keep the rights of employees in terms of creativity and innovation.

7) Increase the volume of business investment.

8) Maintain the confidentiality of information, reduce the risk of loss.

It can also determine the objectives as follows (Alfred 2002)

1) The use of modern digital technologies and systems solutions that would develop the administrative work, thus raising the efficiency and productivity of the employee and the creation of a new generation of cadres efficient.

2) Eliminate the bureaucracy and the complexities of everyday work.

3) Provide information and data for decision-makers quickly and in the right time and raise the level of the regulatory process.

4) Provide advanced technologies in the same relationship that will improve the recovery institutions Economic and attract investment.

5) Reduce operating costs by reducing the quantities of files and cabinets for safe keeping securities and amounts used and achievement of rapid treatment.

6) Bigger and better communication link between a single institution department would provide better services and raise the level of performance.

The benefits of e-governance are: (Saad, .2006) (Mohammed, 2005)

1) Improve the performance and effectiveness of the decision-making by providing information and data to those who want it, and facilitating access to them through their presence on the internal network and access them with minimal effort by means of available search mechanism.

2) Flexibility in the employee's work so that the employee can easily access the internal network from anywhere may exist in which to do the work at the time and place where desired, bringing desktop using electronic management applications does not have can be limits to be out of the house, the street, the airport and other interdepartmental geographically distant.

3) Ease of meetings remotely.

4) There will be no need for the large number of file cabinets and thus providing an area as well as providing dedicated to take care of these files employee expenses.

5) Easy and fast access instructions and transactions for administrative staff and customers and reviewers.

6) Ease ending reviewers transactions through a single point do the job on behalf of the other departments.

7) Ease of storage and archiving of data and information and protection from natural disasters and the factors by keeping backups in places outside the enterprise boundaries.

\section{The areas of Electronic Management}

E-governance takes different patterns and multiple forms consistent with the nature of the work at the facility in order to achieve their goals, and those patterns as follows (Sari2011)

\section{A- E-government}

E-government is one of the electronic management styles, and are intended to manage public affairs by electronic means to achieve political, economic and social goals, and get rid of the routine and the central business high level of transparency.

\section{B -E-commerce:}

E-commerce is the exchange of business information and services via the Internet to achieve economic development rapidly, and bankcards in business operations, and is the first e-commerce application appeared electronic management.

\section{C- E-health}

Thee-health and the provision of consulting services and medical information to patients through electronic means, the patient can follow the results of medical examinations and laboratory tests, information and services across the LAN to the hospital or through the Internet.

\section{D-e-learning:}

In the e-learning, one can conduct the study and tests editorial and discuss scientific messages via LAN facility or through the Internet.

\section{E-Mail publication}

Through electronic publication, one can follow breaking news and economic and social bulletins and access to the latest literature, and take advantage of the various search engines and achieve rapid access to the information from the original sources. From the above, researcher concluded that e-governance comes in the forms of multiple and diverse as, and therefore no organization is complete without the other, but permeated all institutions, whether educational or other terms determine the pattern of these patterns nature practitioner working in those institutions.

\section{Human Resources}

\section{Concept of human resources}

We have variety of views in defining the concept of the latter, where they can distinguish between two different, two modern and traditional owners of the traditional view or classic believes it is only a routine activity respect to things that have no effect on the productivity of the institution. For example, save the files and records of employees and follow activities related to them, Kill presence and they left and vacation times, and reflected on the role of the performance of function and structure of public regulatory institution, Only in this narrow view were not the only organ limited importance does not amount to a major management in the enterprise level, such as plant management or business administration and others see.

On the other hand, the point of modern owners considering the believe that human resources management is one of the 


\section{International Journal of Science and Research (IJSR) \\ ISSN (Online): 2319-7064}

Index Copernicus Value (2013): 6.14 | Impact Factor (2014): 5.611

basic functions in the organization and have the same importance of other functions - Supply, marketing - because of the role played by the human element in influencing the production enterprise. (Alsalmi 1985)

Bélanger also defined as "a set of activities that focus on the development and maintenance of human resources needed by the organization to achieve its objectives and to highlight these activities are: recruitment, training, promotion, work positions. (Bélanger1984) all the processes related to management in general, the planning, organizing, guidance, supervision, monitoring and evaluation of all processes and activities that lead to the greatest human resources efforts, so as to achieve the objectives of the organization and individual goals. (Bassiouni2005)

Administrative activities related to access to the organization of human resource needs and develop, motivate, and maintain, as can achieve organizational goals at the highest levels of efficiency and effectiveness (Jamal 2005) a set of rules and procedures applied by the institution, which oversees the range of activities related to the human element in the organization where you search for qualified labor tires for the right man in the right place and access to the efficiency and production of the hand of individuals and the organization. (Hamdi1985)

The management of human resources, is one of the basic functions in the enterprise, and its importance for those production jobs, marketing, finance, and so the importance of the human element and its impact on the productive efficiency of the facility. (Salah 2007)

\section{Strategic importance of human resources}

The human resource management is central to most of the relations between the organization and its employees, and to achieve its strategic goals and objectives and the importance that is given back to the function of human resources management for the following reasons (Bziav .2010)

A -Studies and Research: Several research has shown the need for care of the human element as a key factor to increase production, and the increasing recognition of the importance of human relationships and motivate employees and satisfy their needs because the success or failure depends on established human element.

B -Cost: T-formation activities the organization needs to cover the wages and compensation of employees, a large part of the expenses of the Organization.

C- the need for specialization: require the practice for human resources management which requires rehabilitation and training of specialists in many aspects, we have to impose such interference new burdens on people management, is to draw a deal with the human element under the laws and regulations policy despite the fact that a lot of departments Supreme does not pay much attention to human resources, and they pour all their concerns on the material resources or give the most attention, as research studies conducted on some of the companies, which has continued over the years proved (Hashem 2007)
And achieved great success, have a good manpower policies, and those that did not continue or failed to achieve its goals was to double the policies in the field of manpower and labor relations in which the bad and be healthy, and an explanation of the importance of human resource management mention the following:

- The human resources management leads to better targets.

- The new management of human resources leads to minimize the conflict between management and labor or employees, any improvement of the relationship between management and other devices.

- Adapted to human resources management and adapt to the restrictions surrounding the organization and environmental conditions in which the most important labor laws for government legislation.

- The human resources management in the new organization leads to the creation and development of the work force to beg rainy at the work, which means higher per capita productivity as a result of appropriate regulatory climate in the organization and presence.

- The new management of human resources is a prerequisite to achieve job satisfaction in the organization and raise the morale of their employees

\section{The Goals of Human Resources}

Human resource management objectives are divided into two types: They are participation and effectiveness:

A. Post: types of goals is the first real meaning lies in the selection of capable human resources to achieve the goals of institutions, as the work of human resource management team in the labor market may exist to choose between the available workforce, which commensurate with the goals of his administration.

B- efficiency: is the second types of goals, and purpose of making the workforce accomplish that is asked of them successfully and perseverance, and is known as the effectiveness linked to a large extent by several elements notably motivate individuals and develop their abilities and provide them with the skills and resources to help them unwanted communication(Hassan 2002)

The changes imposed by the electronic management of human resources.

Electronic management application on human resources produces the following changes:

\section{Organizational changes:}

A. Increased need for indirect employment within the organizational structure, increasing the proportion of direct labor, will increase the need for specialist functions such as research and development and maintenance technicians to deal with the most complex equipment.

B. Increased need to redesign jobs, and then to re-analyzed and described.

C. the emergence of the need to change the performance of the new jobs, as would input devices.

D. Information and communication technology that contributes to increase the capital cost or the cost of investing in these devices and increasing allocations of 


\section{International Journal of Science and Research (IJSR) \\ ISSN (Online): 2319-7064}

Index Copernicus Value (2013): 6.14 | Impact Factor (2014): 5.611

ownership. The combined technological development to increase or reduction in operating costs, which requires there design cost criteria, or may be combined with raising the quality, which requires re-quality design, and technological development leads to poor performance of certain process time, which requires re-design or determine the scheduling criteria.

E. The emergence of the need to provide administrative leadership to the concept of empowering employees and building work teams responsibility, through conscious choice and distinct individuals, and prepare them for the exercise of this empowerment.

F. The need to supply information technology and its application to appear to help more flexible and higher speed of organizational communications. Application of information technology abroad, has led, with thereengineering processes to reduce bureaucracy and features a series of power, and to integrate more between the purchase and production processes and make organizational communications higher speed and more slender.

\begin{abstract}
A change in the structure of human resources:
It is natural that the change results in equipment and working methods, either in production or shopping or financial management or in research and development. A change in the structure of employment, the transition to an automatic performance or full automatic machines and the use of computers will reduce execution manual and clerical workers, and non-skilled in general, but they will increase the need for technical manpower in the field of employment, as well as to skilled labor in the areas of operation and maintenance.
\end{abstract}

Here, managers should anticipate such changes and prepare for them, and have faster switching when automation is part of the expander in production capacity or to a crisis within the new project facilities, and therefore does not pose such a threat to the transition for workers in existing jobs. In other cases it is necessary to prepare workers to shift to other jobs through retraining. Before the opening of the new Chryslerau to plant in Michigan in 1995, and put their employees in training programstook900,000hours of training.

In factories design programs subsidized computer engineers reduced the traditional rulers engineering drawing campaign. In the services sector reduced assigned to read and record commodity prices and tax calculation and the remaining amount required and the amount of preparation required for staff to collect the cash and they were doing traditional calculations in a longer time than it takes for these machines electronic machines.

\section{Research and Development Programs}

Not associated with technological developments have increased investment in automation equipment more or less on research and development programs. They fuel the engine of technological development and secretions of new products and new methods of performance in the areas of production, marketing, financial and human processes. And requires the establishment and development of modules for research and development create and develop specialized cadre of researchers through an integrated combination of education, training and technology.

\section{Information Technology}

Moreover, the technological development also requires an investment in the information that is a mix of communications technology and computer technology. Electronic technology has become the technology of information now is: the main intake of technological development, and will continue so in the future too. This will require the quest to create a team of IT specialists at each institution. Stunning development has increased in the industry and information technology of the danger of information as a strategic resource. The Who owns the information technology and the knowledge of those who have a stronger funds. The owner has the first and the development of ways to create money. The owner of IIAlamoal- they may be lost if there is no confirmed information for managing and identifying influential source of competitiveness.(Ali2007)

The implications of technological development on the training performance:

Whenever changes in performance equipment and methods, and increasingly diverse training needs of workers, which needs to be developed to keep pace with new technology, where the need for repeated with pursuing technical variables. Butwe can say that today's college graduates will need training ranges ten times on average over the course of their careers.

\section{Conclusion}

Allowing for the electronic management of human resources management in the organization opportunities through modern means and methods provided by this administration, is that the employee must have the following characteristics are available:

- The ability to capture information and convert it into usable knowledge.

- The ability to air-conditioning and learning quickly, owning skills crisis so.

- Proficiency in working with technical information on computer-based technology and its applications in the field of work.

- The ability to cooperate and work within a team, and mastery of verbal and written communication skills and default.

- Owning Extra Special skills are different from traditional skills in routine work.

- Proficiency in more than one language is even necessary while working in a global business environment.

- Proficiency in work outside the boundaries of space and time, and the ability to manage work, whether in traditional work environments or virtual environments.

- The ability to identify the needs and desires of consumers own unique individuals or institutions and bodies, is no longer with the unified standard specification products to suit everyone.

\section{Volume 4 Issue 11, November 2015}




\section{International Journal of Science and Research (IJSR) \\ ISSN (Online): 2319-7064}

Index Copernicus Value (2013): 6.14 | Impact Factor (2014): 5.611

\section{References}

[1] Mohamed B.Mel Baradei, the development of human resource planning skills, scientific evidence, I 1, Aptrakfor publication and distribution, Cairo. (2005).

[2] Bélanger: B "Gestion des resource's humaines », Approche systémique, Ed, Gaèton .Morin, Québec, (1984).

[3] Fair, B.F the effectiveness of human resources management in achieving job satisfaction among university staff, unpublished Master Thesis, Faculty of Humanities and Social Sciences, University Mentoz Ksenana, Algeria. (2010).

[4] Clay. M. Technology Competencies of Beginning Employee: A Challenge and Opportunity for Employee Preparation Programs". Dissertation Abstracts International, (2000).

[5] Jamal.a Mohammed Mursi, strategic management of human resources, the entranceto achievea competitive advantagefor the organization atheist century, the house of the university Alexandria. (2005).

[6] Hassan.I Oak, human resources management a strategic perspective, Arab Renaissance Publishing House, Lebanon, CT 1.(2002).

[7] Hamdi.M, and management functions, the Arabencyclopedias. (1985). Ho, Alfred T.-K. Reinventing Local Governments and the e Government Initiative. Public Administration Review 62 (2002).

[8] Sari.A, obstacles application of e-governance in Palestinian universities, unpublished Master Thesis, Arab Research and Studies Institute, Cairo, (2011).

[9] Saad .A, informatics development plan in Saudi Arabia, Al-Faisal magazine, Issue 309, Dar al-Faisal.

[10] Saad.Gal-Tikriti and Bashir Abbas Keywords, ebusiness, Dar curriculum for publication and distribution, Oman. (2002).

[11] Salah .A, Abdul Baqi, human resource management, modern university office, Cairo, Egypt. (2007).

[12] Abdel .F, e-government, Knowledge House, Cairo. (2003).

[13] Abdel .F, the legal system for the protection of egovernment, Dar university thought, Alexandria. (2004).

[14]Ali .A management and competencies productivity, strange publishing house, Cairo, (1985).

[15] Ali .A, "the competitive entrance systemic management, administrative bulletin of the Arab Associationfor Management, Issue March 15, March (2007).

[16] Fathi MohammedAbdel-Ghani, business re-engineering and electronicadministration, "a symposium on the impact of the Internet governance in government institutions," the Arab League, the Arab Organization for Administrative Development, Cairo. Egypt. (2006).

[17] Mohammed.B, the success of the application of electronic transactions STC, Master Thesis submitted to the Council of the College of Business Administration, King Saud University, Saudi Arabia .(2007).

[18] Mohammed Mohammed Hadi, e-learning via the Internet, the Lebanese house Egyptian, Cairo. (2005).

[19] Hashem. A, et al., University education management. (2007).
[20] Nayef. A, the obstacles in the e-learning applications, unpublished Master Thesis, Mutah University, Jordan. (2005).

[21] Nagam Abboud Nagam, Electronic management and strategic functions and problems, Sunrise House, Riyadh(2004).

[22] Nagam. A, Japanese entrance to the Department of Operations, House Warraq for publication and distribution, Oman. (2004).

[23] Raafat.R, the world of e-commerce, the Arab Organization for Development, Cairo: (1999). 